\title{
Dimensões estratégicas e limites do papel da educação para o desenvolvimento brasileiro
}

PAULO ROBERTO CORBUCCI Instituto de Pesquisa Econômica Aplicada

O propósito maior deste estudo é o de discutir a relação entre educação e desenvolvimento no contexto atual da sociedade brasileira, tendo-se como pano de fundo a condição sistêmica de uma economia altamente globalizada.

Parte-se da premissa que considera que o desenvolvimento não é factível a todos os países, ao menos nos padrões alcançados por aqueles que integram o chamado Primeiro Mundo, tendo em vista que a dinâmica do capitalismo ocidental conferiu papéis distintos aos integrantes de um sistema-mundo que, em sua construção, foi delineado pela relação Centro-Periferia.

Ao mesmo tempo, e apesar de se reconhecer que o desenvolvimento de uma nação não se concretiza sem uma educação de qualidade, acredita-se que a esta vem sendo atribuído um poder de mudança que, quando dissociada de fatores tais como emprego e renda, saneamento básico, nutrição, segurança, tende a apresentar efeitos limitados. Portanto, para tornar a educação de qualidade factível a todos, urge reconhecê-la e tratá-la a partir de suas interfaces com estas outras áreas e campos de intervenção social.

Diante do exposto, busca-se responder à seguinte questão: em que medida o padrão educacional brasileiro atual estaria comprometendo o desenvolvimento do país e como este, em seu estágio presente, estaria interferindo na qualidade da educação? 
Trata-se, pois, de analisar a relação entre educação e desenvolvimento como uma via de mão dupla, distanciando-se, assim, de uma concepção mecanicista pela qual mais educação aponta necessariamente para maior desenvolvimento do país.

Portanto, pelo enfoque aqui adotado, reconhecem-se potencialidades e limites da educação diante do desafio de transformar a sociedade brasileira, marcada por profundas desigualdades de diversas ordens, em uma nação economicamente dinâmica e socialmente justa.

\section{CONCEPÇÃO SISTÊMICA DE DESENVOLVIMENTO}

Compartilha-se do entendimento de que o processo de globalização econômica constitui um desdobramento histórico-estrutural do desenvolvimento capitalista, favorecido e intensificado pela expansão marítima europeia iniciada no século XV (Corbucci, 2003).

Desse processo resultou a divisão da humanidade ou, mais propriamente, dos Estados-nação, em Centro e Periferia. Por esse enfoque, a condição periférica não deveria ser entendida como uma "opção" nacional, de cunho voluntarista, mas como um desdobramento necessário da mundialização do capital, que conferiu determinados papéis às distintas regiões do planeta, estabelecendo assim uma clara divisão internacional do trabalho. Acredita-se que tais papéis ou funções foram atribuídos e assumidos em virtude de condições objetivas que favoreceram o seu desempenho, entre as quais a dimensão geoclimática.

Paradoxalmente, as regiões mais ricas em recursos naturais, e/ou que forneciam produtos primários de alto valor no mercado europeu, foram justamente aquelas que suportaram, ao longo dos últimos quinhentos anos, o fardo mais pesado em razão dos processos de espoliação e expropriação estabelecidos pelo capitalismo ocidental. Por sua vez, aquelas regiões que não tiveram suas riquezas expostas à avidez da exploração colonial, inicialmente por guardarem semelhanças geoclimáticas com o continente europeu, de alguma forma foram poupadas do desempenho dessa função subalterna no sistema capitalista mundial. Desse modo, puderam tornar-se espaços de acolhida dos excedentes populacionais europeus, tal como ocorreu com os Estados Unidos da América, Canadá, Austrália e Nova Zelândia e, em menores dimensão e intensidade, com a porção meridional da América do Sul.

De tal ótica, o status de nação periférica não estaria necessariamente vinculado à variável temporal, a um atraso histórico que deveria ser superado a partir de um processo de adequação ou modernização. Boa parte dos países ricos, senão a maioria, só ingressou na era industrial durante a segunda metade do século XIX, momento em que toda a América Latina já se encontrava formalmente liberta do jugo colonial e, portanto, apta a desencadear processos semelhantes. Mas, diferentemente dos primeiros, a autonomia política das jovens nações latino-americanas foi condição necessária para estabelecer-se a hegemonia inglesa nessa parte do continente americano. 
Desde o início, a forma de inserção dos países latino-americanos no mercado mundial implicou a edificação de estruturas sociais profundamente desiguais, resultantes dos padrões de geração e apropriação da riqueza produzida.

No caso brasileiro, a desigual apropriação da renda, que aqui remonta ao período colonial, não foi alterada com a Independência em 1822, haja vista que as principais riquezas continuaram a ser produzidas sob a égide da escravidão, que perdurou até quase o final daquele século. Ao mesmo tempo, foi negado aos que produziam tais riquezas o acesso à educação e, consequentemente, a falta desta foi o legado herdado pelos seus descendentes.

Assim como ocorreu com a Lei Áurea, o advento da República não foi suficiente para transformar radicalmente tal situação, na medida em que sua primeira fase, conhecida por República Velha, esteve sob o controle das oligarquias agrárias.Não é de estranhar que, no período de 1900-1930, a taxa de analfabetismo no Brasil tenha ficado praticamente estagnada, caindo apenas cinco pontos percentuais e situando-se em torno de $60 \%$. A título de comparação, em igual período, a taxa de analfabetismo na Argentina reduziu-se à metade, tendo atingido 25\% (Fausto; Devoto, 2004).

Diante desse legado histórico, os chamados países emergentes têm pela frente pelo menos dois grandes desafios. O primeiro refere-se à redução dessas desigualdades internas, que resultaram do tipo de inserção no mercado mundial. Já o segundo desafio remete ao embate político-econômico em prol de uma maior equidade nas relações de troca com os países ricos, ou seja, algo como uma revisão da também histórica Divisão Internacional do Trabalho.

A concretização de um padrão de desenvolvimento que se aproxime do alcançado pelos países do chamado Primeiro Mundo dependerá do grau de sucesso resultante do enfrentamento desses dois desafios. Mas, mesmo sendo otimista, é pouco crível que o padrão de desenvolvimento a ser alcançado seja o mesmo que o atingido pelo Centro capitalista. Conforme mostrou Arrighi (1996), as desigualdades na apropriação da renda entre países ditos desenvolvidos e em desenvolvimento foram sensivelmente ampliadas ao longo do século XX.

Para os propósitos deste estudo, no entanto, a análise ficará restrita ao primeiro desafio, sobretudo no que tange à educação como fator de desenvolvimento, redução das desigualdades socioeconômicas e promoção da cidadania.

\section{A ESTREITA RELAÇÃO ENTRE RENDA, EDUCAÇÃO E DESENVOLVIMENTO}

As condições de vida da população, entre as quais nível de renda, habitação, saneamento, saúde e nutrição exercem influência decisiva sobre o desempenho escolar dos estudantes. Desse modo, parcela significativa das crianças e dos jovens brasileiros logra baixa aprendizagem escolar que, via de regra, resulta em sucessivas reprovações e na ampliação do tempo necessário para conclusão do ensino fundamental. Muitos 
desistem de prosseguir nos estudos ou acabam por ingressar no ensino médio noturno, conforme evidenciam estudos como os de Abramovay e Castro (2003) e Marques (1997), que oferece um tipo de formação que fica a desejar em relação ao ensino diurno. Portanto, condições de vida precárias comprometem rendimento e trajetória escolares que, por sua vez, contribuem para reproduzir desigualdades sociais existentes.

Apesar de se partir de uma concepção de desenvolvimento que vai além da dimensão econômica, torna-se necessário analisar indicadores dessa natureza, tais como renda per capita, no intuito de verificar quão estreita é a sua relação com a educação.

Parece existir, enquanto regra geral, certa correlação entre escolaridade e renda, ainda que alguns países constituam pontos fora dessa curva de tendência. Exemplo clássico disso é o caso cubano, onde os progressos educacionais não foram acompanhados de equivalente incremento de renda. Apesar de o analfabetismo ter sido erradicado e o acesso de crianças e jovens à escola ter sido praticamente universalizado, os padrões de renda e consumo alcançados no chamado Primeiro Mundo ainda são uma miragem para a sociedade cubana. É bem provável que a explicação para esse desvio a tal regra geral esteja relacionada às estruturas políticas e econômicas vigentes naquele país, que o colocam em situação peculiar em relação ao restante do mundo. De qualquer modo, o caso cubano mostra que a educação per se não é capaz de promover o aumento da renda, independentemente de fatores políticos e econômicos.

No caso brasileiro, a relação direta entre renda e educação parece mais clara, especialmente quando se desagregam diversos indicadores educacionais segundo faixas de renda. Por exemplo, quando se analisa a incidência do analfabetismo por grupos de renda distintos, encontram-se diferenças de cerca de dez vezes entre eles, tal como mostra a tabela 1 .

Tabela 1 -Taxas de analfabetismo da população de 15 anos ou mais, por faixas de renda - Brasil e Grandes Regiões (2009)

\begin{tabular}{l|c|c}
\hline & até 1 salário mínimo & mais de 2 salários mínimos \\
\hline Brasil & 14,6 & 1,4 \\
Norte & 13,0 & 2,0 \\
Nordeste & 22,2 & 2,4 \\
Sudeste & 9,0 & 1,1 \\
Sul & 9,4 & 1,1 \\
Centro-Oeste & 11,3 & 1,6 \\
\hline
\end{tabular}

Fonte: PNAD/IBGE.

Elaboração do autor.

Conforme se observa pela tabela 1 , os índices de analfabetismo são bastante díspares entre aqueles que têm renda de até um salário mínimo e os que recebem mais de dois salários mínimos. São diferenciais significativamente maiores que os 
encontrados a partir de variáveis tais como localização regional, do domicílio (rural/ urbana), faixa etária, raça/cor.

Mesmo com o recente aumento da renda entre os mais pobres, que levou a uma redução da população que vive abaixo da linha de pobreza, não houve elevação do nível de escolaridade desse segmento populacional, ao menos no que se refere à redução do analfabetismo. No período 2004-2009, reduziu-se o universo de pessoas com rendimentos de até meio salário mínimo e, consequentemente, aumentou a quantidade daquelas que recebiam mais que meio até dois salários mínimos. Porém, conforme mostra a tabela 2 , esse aumento também foi acompanhado de ampliação da taxa de analfabetismo de pessoas com renda maior que um até dois salários mínimos.

Tabela 2-Evolução do analfabetismo segundo faixas de renda Brasil 2004-2009

\begin{tabular}{|c|c|c|c|}
\hline & 2004 & 2009 & Var. \% \\
\hline \multicolumn{4}{|l|}{ Pop. 15 anos ou mais } \\
\hline Com renda de até $1 / 2 \mathrm{SM}$ & 42.972 .971 & 33.508 .784 & $-22,0$ \\
\hline Com renda $>1 / 2 \mathrm{SM}$ até $1 \mathrm{SM}$ & 37.127 .419 & 40.833 .090 & 10,0 \\
\hline Com renda $>1$ até $2 \mathrm{SM}$ & 26.478 .846 & 36.782 .246 & 38,9 \\
\hline \multicolumn{4}{|l|}{ Taxas de analfabetismo } \\
\hline Com renda de até $1 / 2 \mathrm{SM}$ & 18,7 & 16,4 & $-12,3$ \\
\hline Com renda $>1 / 2 \mathrm{SM}$ até $1 \mathrm{SM}$ & 13,5 & 13,2 & $-2,2$ \\
\hline Com renda > 1 até $2 \mathrm{SM}$ & 5,1 & 6,3 & 23,5 \\
\hline
\end{tabular}

Fonte: PNAD/IBGE.

Elaboração: IPEA.

Como pode ser observado na tabela 2 , a quantidade de pessoas cuja renda não ultrapassava meio salário mínimo sofreu redução de $22 \%$, em números absolutos, no período em análise, enquanto os dois grupos seguintes tiveram aumentos de $10 \% \mathrm{e}$ 39\%. Desse modo, as pessoas com renda familiar per capita de até meio salário mínimo, que representavam 34\% da população brasileira em 2004, reduziram-se a 24\% desse universo. Provavelmente, a redução da taxa de analfabetismo entre os mais pobres foi devida à transferência de parte dos analfabetos do primeiro grupo de renda para os dois grupos subsequentes.

Outro indicador educacional que também sofre grande oscilação em função da renda é a proporção de pessoas com o ensino fundamental completo. Até 2009, esse nível de ensino correspondia à escolaridade obrigatória e, apesar de o acesso a ele ter sido praticamente universalizado, parcela significativa dos jovens brasileiros não tem logrado sua conclusão. De acordo com dados da Pesquisa Nacional por Amostra de Domicílios (PNAD) 2009, cerca de um quarto dos jovens de 18 anos de idade não havia completado esse nível de ensino, situação que é agravada com a redução da renda familiar per capita, tal como mostra a tabela 3. 
Tabela 3 - Taxas de conclusão do ensino fundamental na população de 18 anos - Brasil-2009

\begin{tabular}{l|c}
\hline & 2009 \\
\hline População de 18 anos & 75,4 \\
\hline Com renda de até $1 / 2 \mathrm{SM}$ & 58,9 \\
\hline Com renda maior que $2 \mathrm{SM}$ & 93,3 \\
\hline
\end{tabular}

Fonte: PNAD/IBGE

Elaboração: IPEA

Se entre jovens de 18 anos com renda acima de dois salários mínimos pouco menos de 7\% não haviam concluído o ensino fundamental, entre os mais pobres tal proporção atingia $41 \%$ desse universo, ou seja, índice seis vezes maior que o registrado pelos integrantes do grupo de maior renda.

O rendimento escolar de crianças e adolescentes também mantém estreita relação com o nível de renda. Quando se cruzam os resultados da Prova Brasil com a renda familiar per capita, constata-se tendência inequívoca de relação diretamente proporcional, conforme mostra as Figuras 1 e 2.

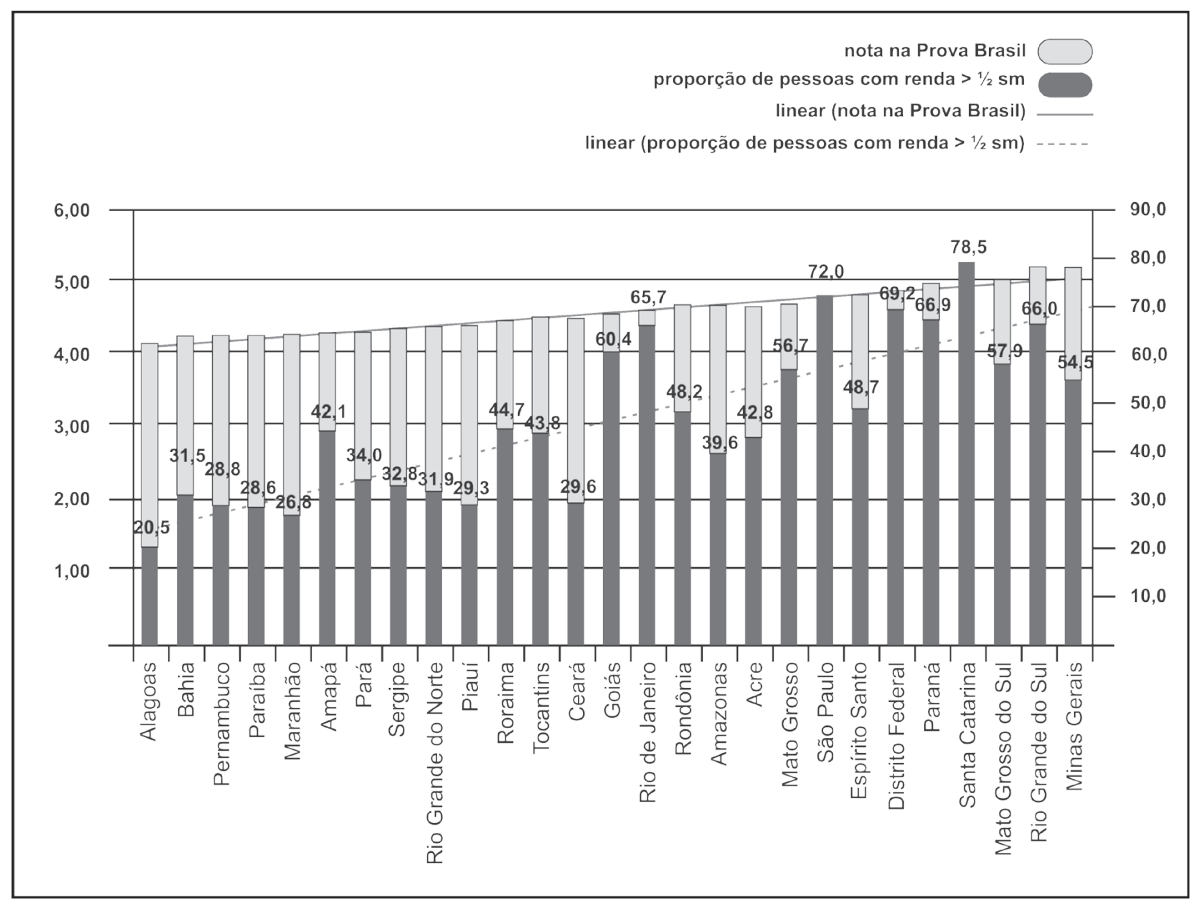

Figuta 1: Resultados da Prova Brasil na $8^{\text {a }}$ série do ensino fundamental, nas redes estaduais de ensino e proporções de pessoas com renda familiar per capita maior que meio salário mínimo, por unidades federadas (2009) (representação em colunas). 


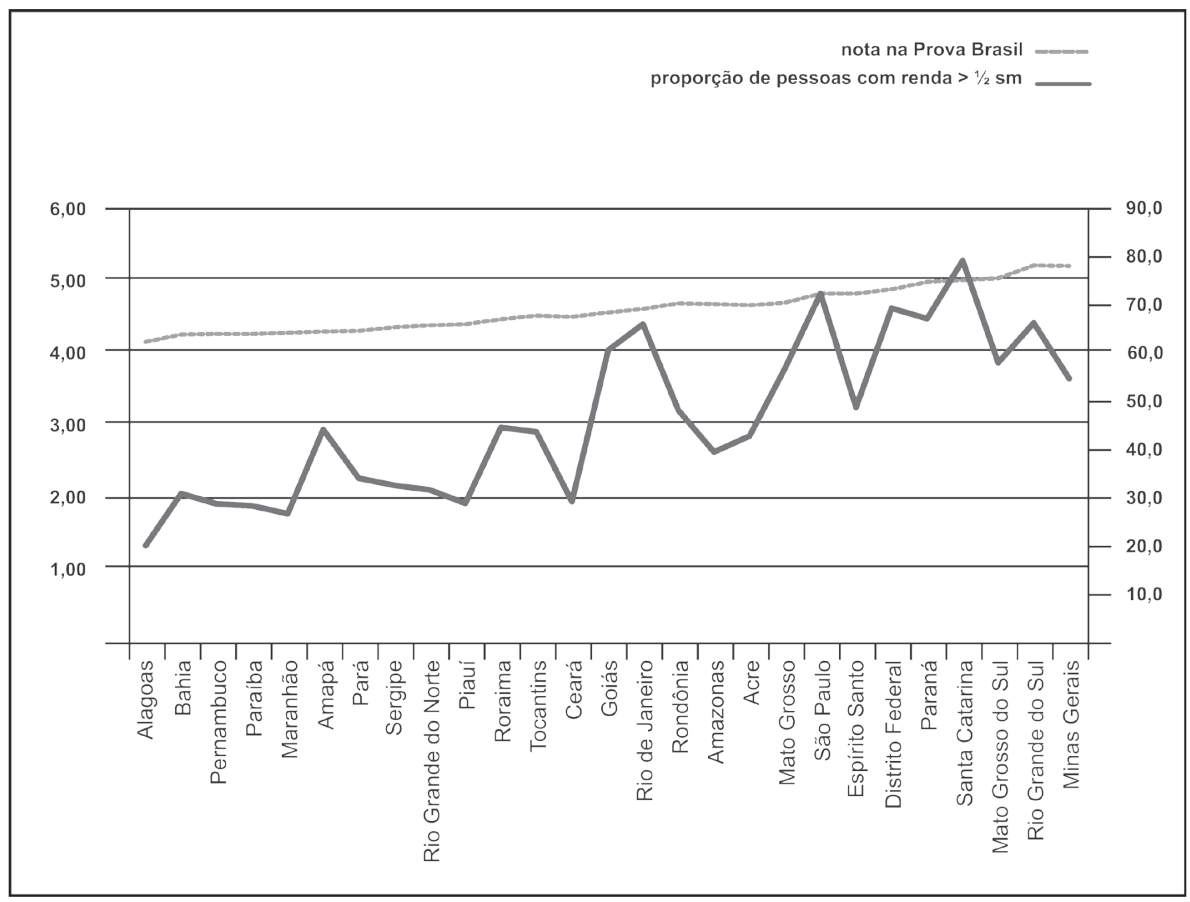

Figura 2: Resultados da Prova Brasil na $8^{\text {a }}$ série do ensino fundamental, nas redes estaduais de ensino e proporções de pessoas com renda familiar per capita maior que meio salário mínimo, por unidades federadas (2009) (representação em linhas).

Fontes: IDEB (INEP/MEC) e renda familiar per capita (PNAD/IBGE).

Elaboração do autor.

Apesar de existirem algumas exceções, o gráfico 1 evidencia que quanto maior a proporção de pessoas com renda familiar per capita acima de meio salário mínimo, por unidade federada (UF), maior é a nota obtida na Prova Brasil. As principais exceções a essa tendência ficam por conta do Rio de Janeiro e Goiás, que, mesmo tendo mais de $60 \%$ de sua população com renda acima desse patamar, obtiveram nota média na Prova Brasil de pouco mais de 4,5 pontos, ao passo que outras UFs com padrão de renda semelhante ou até inferior apresentaram resultados superiores a este.

Minas Gerais é o principal exemplo, pois apesar de ter apenas a $10^{\mathrm{a}}$ maior proporção de pessoas com renda acima de meio salário mínimo, obteve a maior nota na Prova Brasil. Também é digno de nota o estado do Ceará, cujo índice de pessoas que se encontram nessa faixa de renda é um dos menores em todo o país e, mesmo assim, seus estudantes tiveram desempenho mediano na Prova Brasil.

Outro cruzamento que pode ser feito com os resultados da Prova Brasil diz respeito ao estado nutricional das famílias, dado pela proporção de domicílios em situação de insegurança alimentar grave, tal como é apresentado pela Figura 3. 


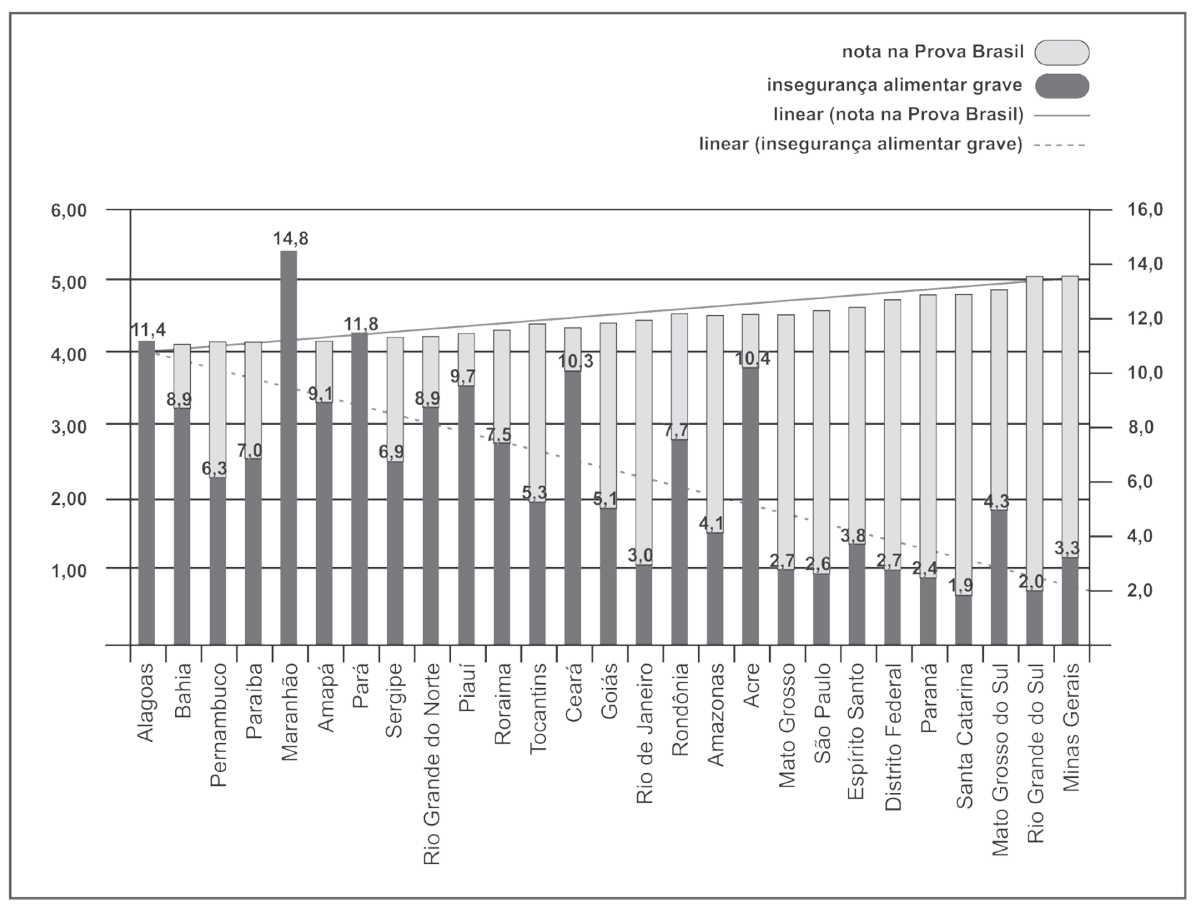

Figura 3: Proporção de domicílios em situação de insegurança alimentar grave e resultados da Prova Brasil na $8^{a}$ série do ensino fundamental, por unidade federada (2009).

Fontes: Prova Brasil (INEP/MEC); Insegurança alimentar (PNAD/IBGE). Elaboração do autor.

Pela análise dos resultados apresentados, constata-se que as UFs com menores proporções de domicílios em situação de insegurança alimentar grave são também as que apresentam os melhores resultados na Prova Brasil. Algumas exceções também são observadas, principalmente Acre e Ceará, que registraram índices de insegurança alimentar superiores a 10\%, ou seja, entre as quatro mais elevadas, mas, mesmo assim, tiveram desempenhos bastante satisfatórios na Prova Brasil, respectivamente $10^{\circ}$ e $15^{\circ}$ lugares.

Também é digna de nota a situação do Maranhão, onde o nível de insegurança alimentar é o mais crítico do país, mas não o suficiente para fazer com que seu resultado na Prova Brasil fosse o mais baixo de todos.

Quando se tem por parâmetro a vertente positiva desse indicador, qual seja, a proporção de domicílios em situação de segurança alimentar, constata-se que cerca da metade das UFs que tiveram as maiores notas na Prova Brasil também são as que apresentaram os maiores índices de segurança alimentar. A Figura 4 apresenta os resultados do cruzamento dessas duas variáveis. 


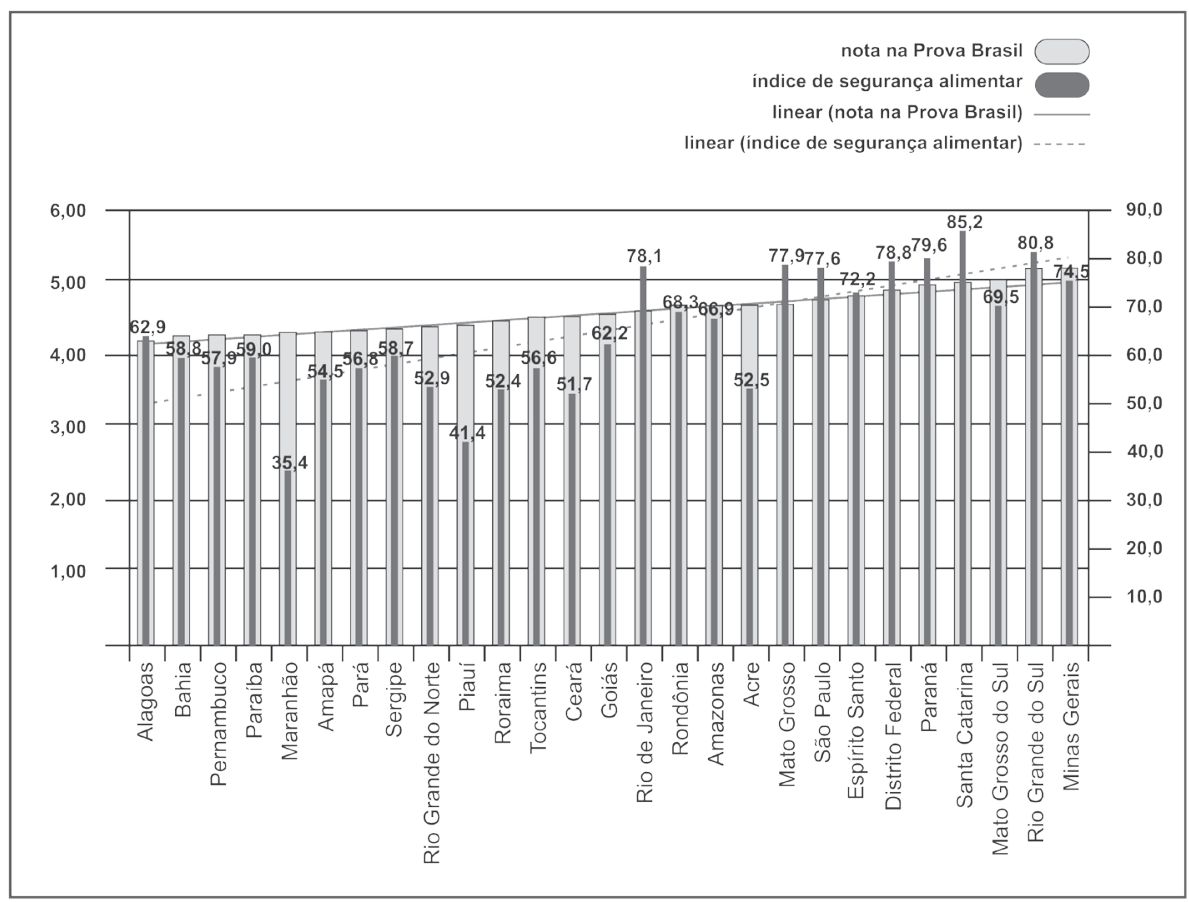

Figura 4: Proporções de crianças em situação de segurança alimentar e resultados da Prova Brasil na $8^{\text {a }}$ série do ensino fundamental, por unidade federada (2009).

Fontes: Prova Brasil (INEP/MEC); Insegurança alimentar (PNAD/IBGE).

Elaboração do autor.

O Acre continua sendo o destaque positivo. Mesmo tendo um dos piores índices de segurança alimentar no país (23a), obteve a $10^{a}$ maior nota na Prova Brasil. Também são dignos de menção os desempenhos do Ceará e Maranhão. No primeiro caso, apesar de ter a terceira pior proporção de domić́lios em situação de segurança alimentar, obteve a $15^{\mathrm{a}}$ nota na Prova Brasil, enquanto que ao Maranhão, que registra a maior proporção de domicílios em situação de insegurança alimentar, coube melhor desempenho na Prova Brasil que os de outras quatro UFs.

Em relação às condições de ensino ofertadas pela escola, optou-se por duas variáveis: o acesso à internet e a existência de biblioteca. A Figura 5 mostra que as UFs com maior proporção de estudantes com acesso à internet foram também aquelas que tiveram maiores notas na Prova Brasil. 


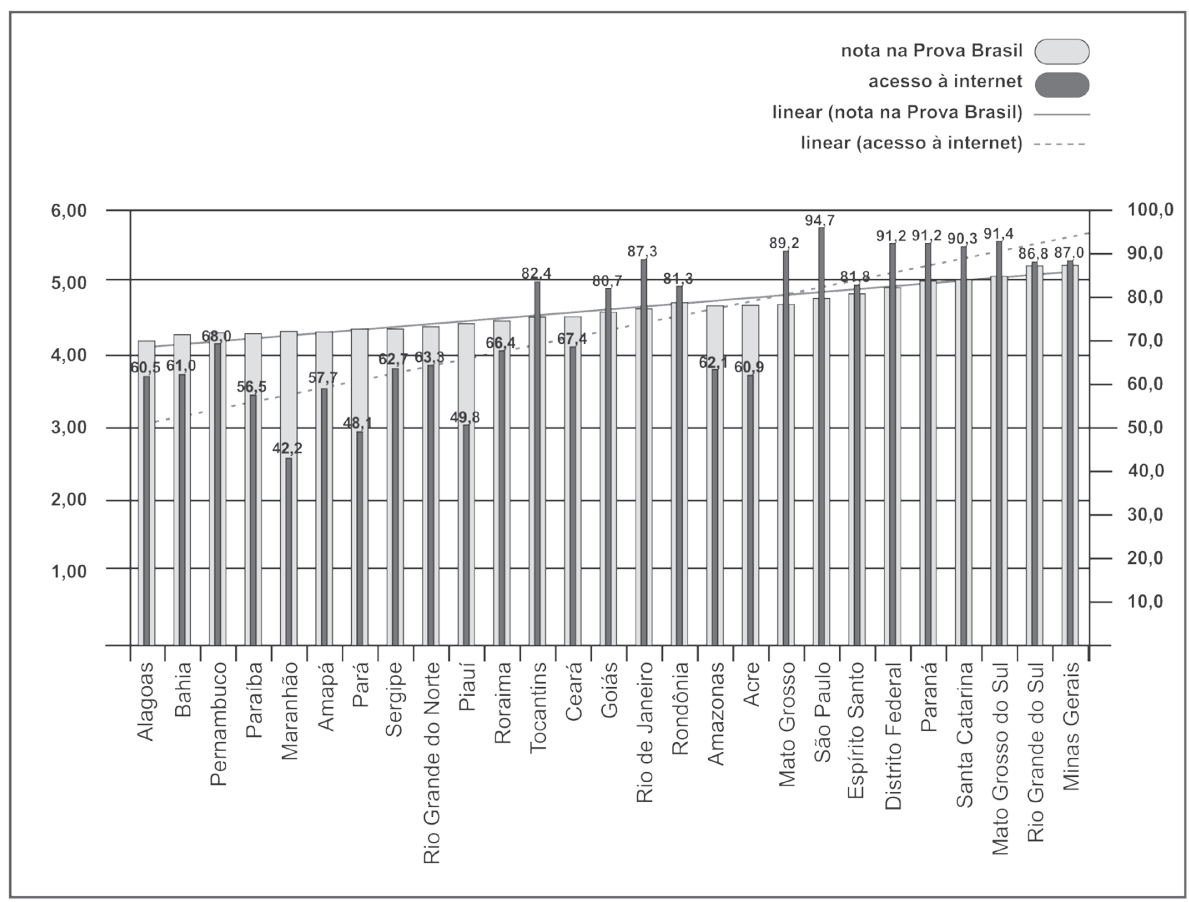

Figura 5: Resultados da Prova Brasil para a $8^{\mathrm{a}}$ série do ensino fundamental e proporções de estudantes matriculados em escolas com acesso à internet, por unidade federada (2009).

Fonte: INEP/MEC.

Elaboração do autor.

Quando se tem em conta, por exemplo, as 11 UFs com menores notas na Prova Brasil (média igual a 4,28 pontos), verifica-se que a proporção de estudantes matriculados com acesso à internet é de apenas 58\%. Mas, para as 16 UFs restantes ampliam-se tanto a nota média na Prova Brasil (4,77 pontos), quanto a proporção dos que têm acesso à internet por meio da escola (83\%).

Em relação ao acesso à biblioteca escolar, a correlação é menos evidente, ainda que se mantenha positiva, tendo em vista que algumas UFs se distanciam da linha de tendência delineada, como São Paulo e Distrito Federal, que apresentaram índice de acesso às bibliotecas escolares abaixo de $50 \%$ e nota relativamente alta na Prova Brasil, ao passo que o Amapá evidenciou relação inversa, como mostra a Figura 6 


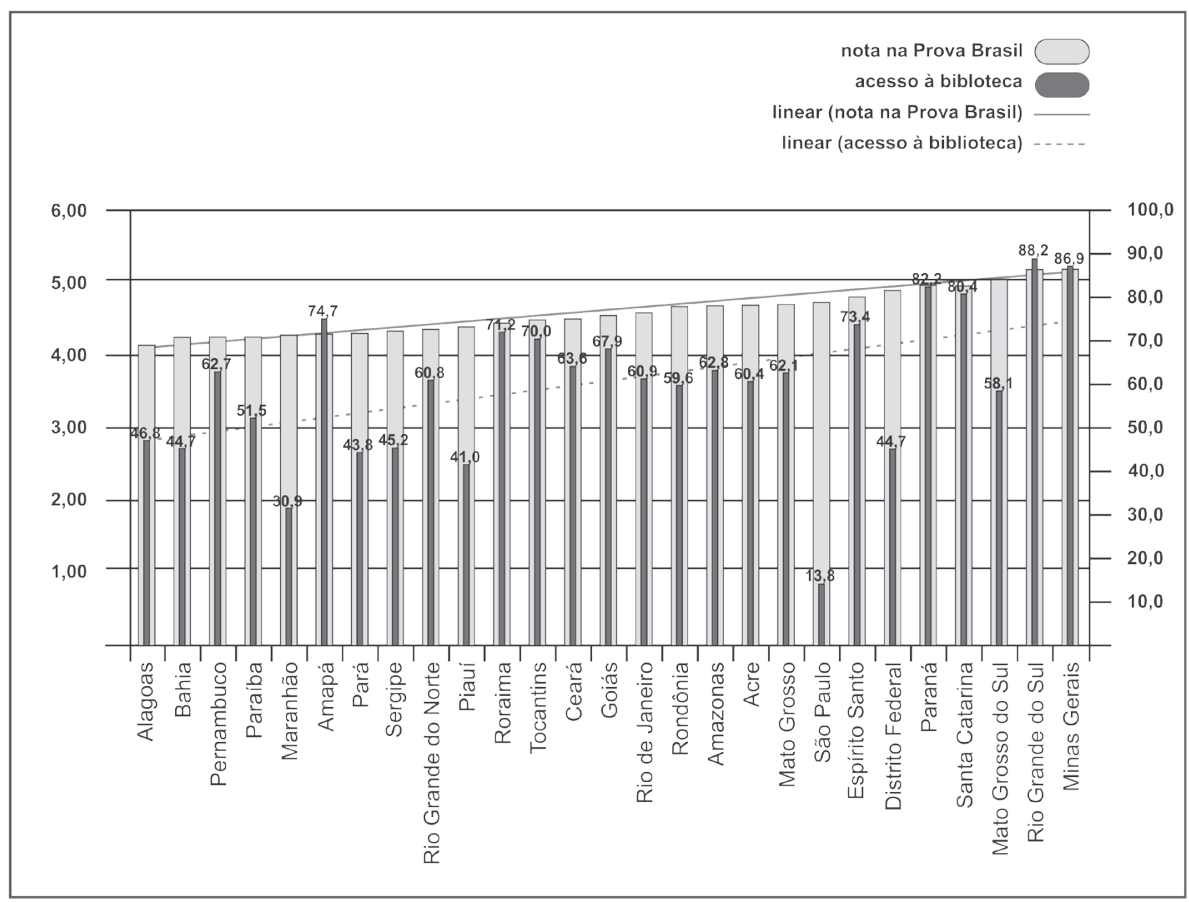

Figura 6: Resultados da Prova Brasil para a $8^{\mathrm{a}}$ série do ensino fundamental e proporções de estudantes matriculados em escolas públicas que têm acesso à biblioteca escolar, por unidade federada (2009).

Fonte: INEP/MEC.

Elaboração do autor.

Tomando-se dois grupos extremos, compostos de cinco UFs cada, verifica-se que as que tiveram pior desempenho na Prova Brasil (média de 4,22 pontos) têm em média apenas $47 \%$ de seus estudantes com acesso à biblioteca escolar. De modo oposto, as cinco melhores UFs naquele exame davam essa oportunidade a $79 \%$ de seus estudantes.

Cabe ainda destacar que entre todos os cruzamentos realizados, esse foi o único em que as duas primeiras colocadas na Prova Brasil também foram as que tiveram maior proporção de estudantes com acesso à biblioteca escolar.

Outra variável relevante para o desempenho escolar de estudantes, amplamente reconhecida pela literatura, diz respeito ao professor. Nesse sentido, optou-se por utilizar o nível de remuneração docente como proxy da qualidade e valorização do magistério. Assim como pode ser observado pela Figura 7, também se verifica tendência positiva entre o valor da remuneração e os resultados obtidos pelos estudantes na Prova Brasil. 


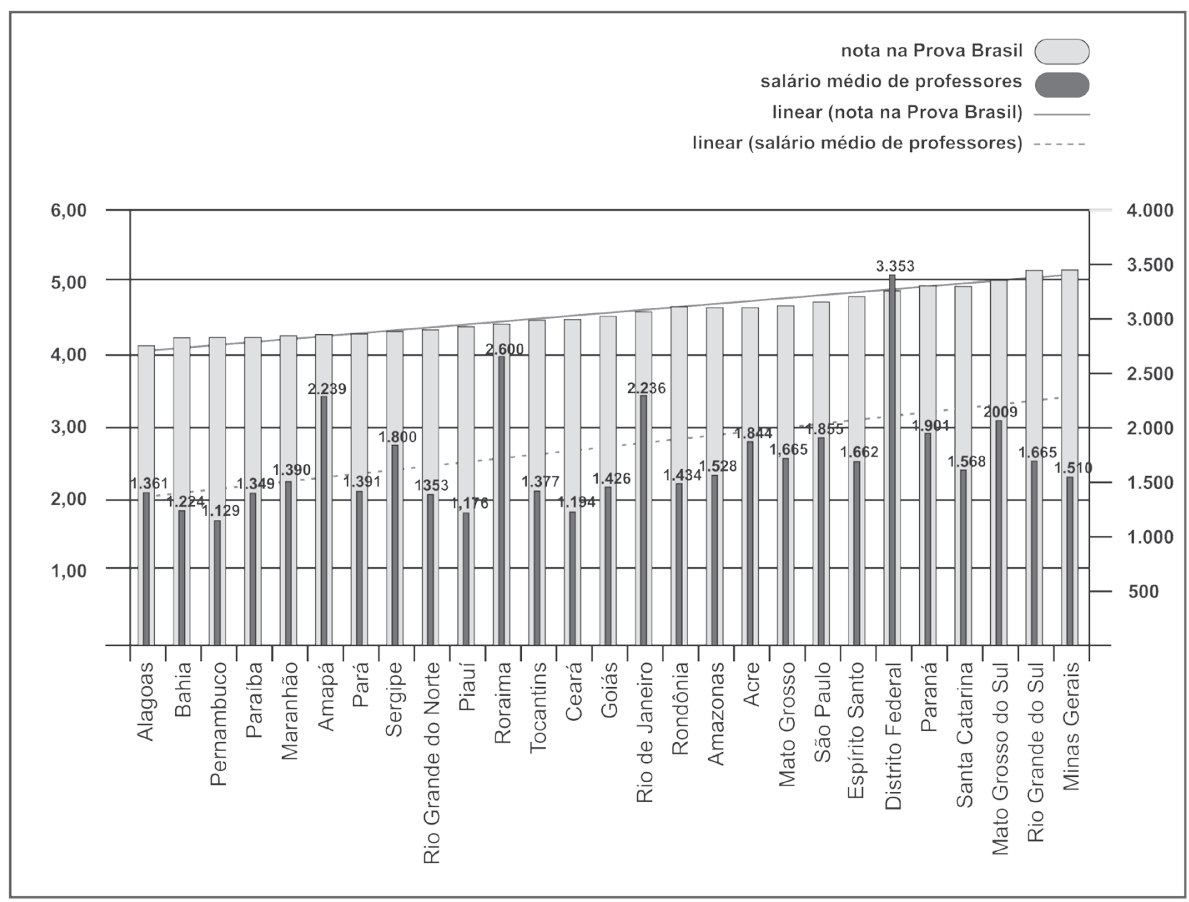

Figura 7: Salário médio de professores nas redes públicas de ensino e resultados da Prova Brasil na $8^{\text {a }}$ série do ensino fundamental, por unidade federada (2009).

Fontes: Prova Brasil (INEP/MEC); Insegurança alimentar (PNAD/IBGE). Elaboração do autor.

Apesar de ter sido delineada tendência positiva entre aumento da nota na Prova Brasil e de salários médios de professores, constata-se pelo gráfico 6 que ao pior resultado nessa prova não corresponde o menor salário, assim como o inverso também não se aplica. Algumas UFs apresentam desvios acentuados em relação à linha de tendência de salários. Distrito Federal, Roraima, Amapá, Sergipe e, em menor grau, Rio de Janeiro registram níveis salariais em descompasso com as notas obtidas na Prova Brasil. Desse modo, ao maior salário médio do Brasil correspondeu apenas a $6^{\mathrm{a}}$ maior nota naquela prova, enquanto ao $2^{\circ}$ maior salário (Roraima) está associada apenas a $17^{a}$ maior pontuação. Em situação ligeiramente melhor se encontra o Rio de Janeiro, que detém o $4^{\circ}$ maior salário médio e se encontra em $13^{\circ}$ no ranking da Prova Brasil. Por fim, o Amapá foi a UF com o terceiro maior salário médio, mas que obteve apenas a $22^{\text {a }}$ maior nota nessa prova.

Os resultados da Prova Brasil também foram cotejados com a receita estimada de gasto por aluno nas séries finais do ensino fundamental, no âmbito do Fundo de Manutenção e Desenvolvimento da Educação Básica e de Valorização dos Profissionais da Educação (FUNDEB), para o ano de 2009, tal como é apresentado na Figura 8. 


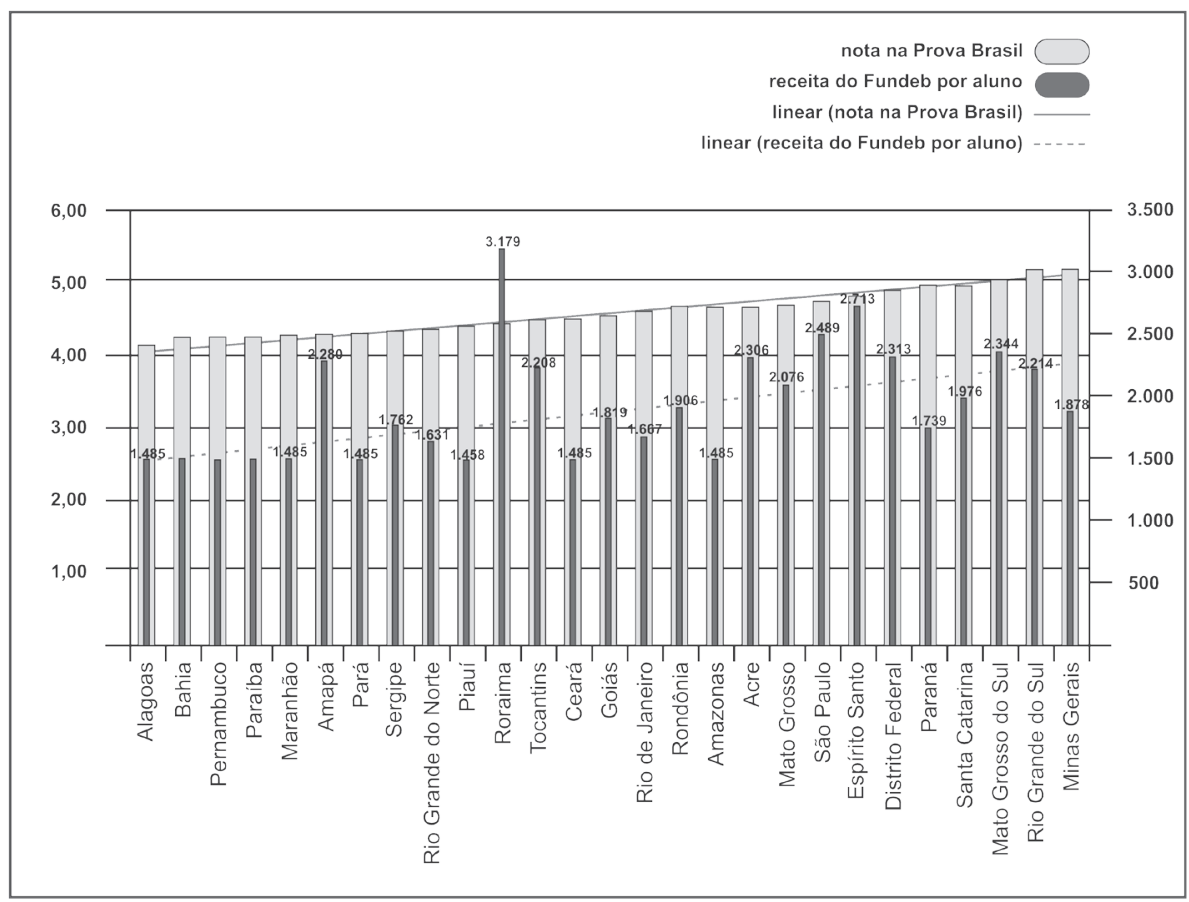

Figura 8: Resultados da Prova Brasil e receita estimada do FUNDEB por aluno das séries finais do ensino fundamental, por unidade federada 2009

Fonte: Prova Brasil (INEP/MEC); Receita FUNDEB(FNDE/MEC).

Elaboração do autor.

Apesar de as cinco menores pontuações na Prova Brasil estarem associadas ao menor gasto por aluno, há alguns casos que se afastam dessa tendência, de forma favorável ou desfavorável. Em situação favorável encontra-se Minas Gerais, com a maior nota na Prova Brasil e apenas a $13^{\mathrm{a}}$ maior receita de gasto por aluno. De modo inverso, mesmo tendo ficado na liderança quanto ao volume de dispêndios por aluno, Roraima obteve apenas a $17^{\text {a }}$ colocação na Prova Brasil.

A baixa qualidade da educação e o incipiente rendimento dos estudantes das escolas públicas brasileiras estão intrinsecamente relacionados a um modelo de expansão dos sistemas de ensino que ficou órfão dos necessários aportes de recursos. Além de o financiamento ainda ser insuficiente, o que compromete em grande medida a qualidade do ensino ofertado pelas redes públicas, as precárias condições socioeconômicas de grande parte do alunado tendem a afetar seu rendimento escolar e a dificultar a continuidade nos estudos, o que é corroborado pelos resultados de exames como a Prova Brasil. 


\section{AS DESIGUALDADES QUANTO ÀS CONDIÇÕES DE ENSINO}

Além de as condições de vida, entre as quais a renda, serem mais precárias nas regiões Norte e Nordeste - por si só suficientes para comprometer o desempenho e rendimento escolar -, por meio da análise dos dados do Censo Escolar 2010, constata-se que as condições de ensino oferecidas pelas escolas públicas também se encontram em patamares bem mais desfavoráveis que os das regiões Sul, Sudeste e Centro-Oeste.

Entre os vários elementos levantados por intermédio desse inventário, foram selecionados cinco itens que guardam estreita relação com a melhoria da dimensão didático-pedagógica. São eles: i) laboratório de ciências; ii) biblioteca; iii) quadra de esportes; iv) laboratório de informática; e v) internet.

As unidades de análise adotadas são escolas e matrículas: em virtude da grande quantidade de escolas rurais que abrigam poucos alunos, haverá maior proporção de escolas sem acesso àqueles itens que a de estudantes matriculados.

Dentre os cinco itens selecionados, a inexistência de laboratório de ciências é a que se torna mais evidente. Cerca de $93 \%$ das escolas públicas brasileiras não dispunham desse tipo de instalação, sendo que tal situação ainda era mais preocupante na região nordestina, onde somente $3 \%$ das escolas contavam com esse tipo de instalação. Quando a unidade de análise passa a ser a matrícula, verifica-se que o índice de privação cai para $77 \%$ do total. No entanto, essa taxa média encobre desigualdades regionais acentuadas. No Nordeste, a proporção atingia $85 \%$ das matrículas, ao passo que no Sul se situava em torno de $57 \%$.

A inexistência de biblioteca escolar continua sendo um fato concreto para $73 \%$ das escolas públicas brasileiras, sendo que no Nordeste essa carência atinge $83 \%$ do total de unidades de ensino. No que se refere às matrículas, constata-se que $46 \%$ destas se encontram em tal condição, mas, quando se comparam regiões, verifica-se elevada disparidade entre o Nordeste (50\%) e o Sul (16\%).

A quadra de esportes também é outra instalação ausente da maioria das escolas públicas brasileiras. Trata-se do local onde deveriam ocorrer as aulas de educação física. Nesse caso, cerca de $75 \%$ delas não dispõem desse tipo de sala de aula. Também é bem mais precária a situação na região nordestina, onde $89 \%$ das escolas não disponibilizam esse espaço aos alunos. Um pouco menos desfavorável é a proporção de matrículas sem acesso, cujo índice cai para cerca de $44 \%$ do total. Entretanto, também são acentuadas as desigualdades inter-regionais. Cerca de 25\% dos matriculados na região Sul, contra $66 \%$ no Nordeste.

Em que pese o fato de a informática constituir ferramenta essencial nos dias de hoje, sobretudo para as novas gerações, os dados do Censo Escolar 2010 revelam que $67 \%$ das escolas públicas brasileiras não disponibilizavam esse tipo de equipamento aos seus alunos. Desse modo, $30 \%$ dos matriculados estavam alijados do acesso a esse tipo de equipamento. Em situação ainda pior se encontravam os 
estudantes residentes na região nordestina, cuja proporção atingia $41 \%$ do total. $\mathrm{Ou}$ seja, mais que o dobro daquela registrada na região Sul (19\%). Considerando-se que as escolas mais afetadas por essa carência são justamente aquelas localizadas em periferias urbanas e áreas rurais, torna-se bastante remota a probabilidade de os alunos aí matriculados terem acesso a computadores.

Do mesmo modo, o acesso à internet também não é disponibilizado pela maioria das escolas públicas. Somente $40 \%$ delas oferecem tal serviço, razão pela qual $23 \%$ dos estudantes matriculados ficam sem acesso à rede mundial de computadores. As diferenças regionais são, nesse caso, bastante acentuadas. Enquanto no Sudeste apenas $9 \%$ não têm acesso à internet, no Nordeste a proporção atinge 40\% do total.

Não é por acaso que os resultados de avaliações de rendimento escolar, tais como o Programa Internacional de Avaliação de Alunos (PISA), têm evidenciado tamanha disparidade quando desagregados pelas redes de ensino existentes, ou ainda pelas UFs. Quando se comparam tais resultados com os dos demais países participantes dessa prova, constata-se a existência de vários "Brasis", conforme se observa pela análise da tabela 4 .

Tabela 4 - Nota média no Pisa 2009

\begin{tabular}{c|c|c}
\hline Classificação & País/Unidade & Média \\
\hline $1^{\circ}$ & Shangai (China) & 577 \\
\hline $2^{\circ}$ & Hong Kong (China) & 546 \\
\hline $3^{\circ}$ & Finlândia & 543 \\
\hline & Cingapura & 543 \\
\hline $5^{\circ}$ & Coreia do Sul & 541 \\
\hline $6^{\circ}$ & Japão & 529 \\
\hline $7^{\circ}$ & Rede Pública Federal (Brasil) & 528 \\
\hline $\mathbf{1 9}^{\circ}$ & Rede Privada (Brasil) & 502 \\
\hline $4^{\circ}$ & Distrito Federal (Brasil) & 439 \\
\hline $5^{\circ}$ & Brasil & 401 \\
\hline $\mathbf{6 4}^{\circ}$ & Redes Estaduais e Municipais (Brasil) & 387 \\
\hline $7^{\circ}$ & Alagoas (Brasil) & 354 \\
\hline $71^{\circ}$ & Quirguistão & 325 \\
\hline
\end{tabular}

Fonte: OCDE.

Elaboração do autor.

Tal como mostra a tabela 4, os estudantes brasileiros pertencentes à rede federal de ensino tiveram desempenho bastante elevado e superior ao da maioria dos países da Organização para a Cooperção e Desenvolvimento Econômico (OCDE). Um pouco abaixo ficaram os alunos das escolas particulares, ainda assim, com índice ligeiramente maior que a média dos países-membros dessa organização. 
Mas, quando a desagregação é feita por UFs, constata-se que a de melhor desempenho, o Distrito Federal, teve resultado equivalente ao do Chile, que foi o país latino-americano mais bem classificado. Porém, quando se compara o resultado de Alagoas, que teve a pior nota no PISA, verifica-se que seu desempenho situava o estado na penúltima posição entre todos os países participantes.

\section{DIMENSÕES ESTRATÉGICAS DA EDUCAÇÃO PARA O DESENVOLVIMENTO}

Assim como são profundas as desigualdades sociais em geral, a educação no Brasil não só reflete tais desigualdades como também tem contribuído para preservá-las e, em situações extremas, ampliá-las. Não se pretende, com isso, afirmar que a educação não esteja contribuindo para a mobilidade social, mas, sim, que isso não se apresenta como regra geral. Certamente, há casos de pessoas oriundas de estratos socioeconômicos desfavorecidos que conseguem transpor obstáculos e ascender na hierarquia social. Porém, os pobres e, sobretudo, os que se encontram em situação de indigência continuam muito distantes daqueles que se enquadram na chamada classe média. Muitos dos que tiveram acesso à educação escolar não lograram atingir um patamar mínimo de escolaridade ou, mesmo tendo atingido, o fizeram sem uma formação de qualidade.

Não há dúvida de que, sem educação de qualidade para todos, a possibilidade de erradicação da pobreza se torna ainda mais remota. Porém, se as políticas educacionais não forem concebidas e implementadas vis-à-vis as demais políticas públicas, no intuito de tratá-las em sua complexidade sistêmica, os avanços tenderão a ser bem menores que os desejados.

Um dos traços que definem a categoria de desenvolvimento é a existência de um padrão socioeconômico e cultural mínimo comum, que permita a cada cidadão se sentir parte do todo e capaz de contribuir para e usufruir dos avanços da civilização. No campo educacional, constituem mínimos necessários o domínio da leitura e escrita, os fundamentos das ciências, da matemática, história etc. Além disso, o compartilhamento de valores demandados pela convivência em sociedade, a aquisição de hábitos de vida saudáveis, enfim, tudo isso concorre para a formação política, o fortalecimento da cidadania e o sentimento de pertencimento.

É justamente a falta desse sentimento de pertencimento, de sentir-se sujeito portador de direitos, que evidencia quão fragmentada é a sociedade brasileira, tal como foi postulado por Buarque (1993). Para esse autor, a globalização das últimas décadas do século XX tem contribuído para naturalizar essa divisão social, a ponto de fazer crer que pessoas são naturalmente diferentes e, portanto, portadoras de direitos distintos.

A inflexão dessa tendência passa, entre outras, pela erradicação do analfabetismo e garantia da educação básica de qualidade para todas as crianças e os jovens 
brasileiros. Trata-se, pois, de assegurar padrões educacionais mínimos, imprescindíveis para que as novas gerações, em sua totalidade, possam sentir-se como cidadãos portadores de direitos já assegurados constitucionalmente.

Por sua vez, o mercado de trabalho ressente-se de profissionais qualificados em número suficiente e com formação adequada às suas demandas, tanto para o setor produtivo, quanto para o preenchimento de vagas ofertadas pelo setor público, sobretudo nas áreas de educação e saúde.

A formação de professores para os demais níveis do ensino constitui uma das principais atribuições da educação superior, reforçada com a vigência da atual Lei de Diretrizes e Bases da Educação Nacional (LDB) (lei n. 9.394/96), a qual estabelece que, ao final da Década da Educação (2001-2011), só serão admitidos para atuar na Educação Básica professores com formação em nível superior.

De acordo com a Sinopse do Professor da Educação Básica de 2009 (INEP, 2011), cerca de 410 mil professores (30\% do total) que atuavam no ensino fundamental não tinham formação em nível superior. Mesmo no ensino médio, onde todos os professores deveriam dispor de tal formação, havia quase 40 mil professores ( $9 \%$ do total) em situação irregular. Esses dados apontam para a necessidade de ampliar-se a oferta emergencial de vagas em cursos de licenciatura, seja na modalidade presencial ou mesmo em cursos a distância.

Tendo em vista que os professores não habilitados se encontram nos estratos de menor renda da categoria, a concessão de bolsas de estudo torna-se condição essencial para viabilizar o ingresso e a permanência deles em cursos superiores. Nesse sentido, a utilização do Programa Universidade para Todos (PROUNI) para essa finalidade tem sido incipiente, na medida em que apenas $1 \%$ dos bolsistas corresponde a professores das redes públicas de ensino.

A insuficiência de professores com habilitação em ciências e matemática constitui um dos principais gargalos do ensino ofertado pelas redes públicas. Uma das implicações negativas desse fato consiste na precária formação lograda por parcela significativa do alunado que, em última instância, comprometerá a empregabilidade e/ou produtividade do trabalho.

Mais que aumentar a oferta de vagas em cursos de licenciatura, torna-se necessário garantir que os egressos desses cursos venham a atuar, de fato, no magistério público. Para tanto, será imprescindível uma política de valorização do magistério mais abrangente, que compreenda, pelo menos, a criação e implementação de planos de carreira, assim como a melhoria das condições de trabalho. Desse modo, seria possível não apenas aumentar, quantitativa e qualitativamente, os quadros docentes da educação básica como, principalmente, evitar a evasão dos mais qualificados que, via de regra, dispõem de outras oportunidades de inserção no mercado de trabalho.

Ao mesmo tempo em que serão imprescindíveis tais medidas para viabilizar o ingresso e a permanência de bons professores nas escolas públicas, torna-se neces- 
sária a implementação de mecanismos de avaliação de seu desempenho, inclusive como instrumento de realimentação constante do processo pedagógico.

Outra dimensão estratégica da educação para o desenvolvimento refere-se aos avanços científico-tecnológicos. A formação de pesquisadores e a consequente geração de conhecimentos são pré-requisitos da inovação tecnológica. Esta, por sua vez, possibilita a agregação de valor aos bens e serviços produzidos, além de diminuir a dependência externa mediante substituição de importações por produtos nacionais, de modo que reduza a evasão de divisas.

A participação do Brasil em relação à produção científica mundial vem sendo ampliada em ritmo acelerado. Em 1985, o país respondia por apenas 0,5\% do total de artigos publicados em periódicos indexados junto às bases de dados do Institute for Scientific Information (ISI). Em 2008, a participação brasileira havia atingido $2,1 \%$, suficiente para colocar o país em $13^{\circ}$ lugar.

Apesar de ter sido expressiva a evolução da produção científica brasileira, esta não tem sido acompanhada, em proporção semelhante, de inovações na forma de bens e serviços, o que já vinha sendo atestado por Lastres (1997) e, mais recentemente, por amplo estudo realizado por pesquisadores do IPEA (2005).

Conforme analisa Corbucci (2007), pelo fato de haver uma nova configuração dos sistemas produtivos, sob a égide da globalização:

caberia à maioria dos países do chamado Terceiro Mundo desempenhar papel de consumidores de conhecimento e tecnologias [...] ou, quando muito, de responderem pela montagem de bens industrializados, com o correspondente baixo valor que essa etapa do processo produtivo agrega ao preço final do produto.

Ainda que o Brasil tenha alcançado projeção mundial em termos de inovação tecnológica em alguns setores produtivos, tais como na exploração de petróleo em águas profundas, produção de biocombustíveis e no agronegócio, o que se observa é que esses avanços não foram suficientes para reestruturar a pauta de exportações, na qual as commodities, além de predominarem, vêm crescendo em participação.

Apesar dos incentivos e do financiamento concedidos à pesquisa pelo Poder Público, no Brasil, a transformação do conhecimento produzido em inovações e tecnologias dependerá do grau de articulação entre institutos de pesquisa e setor produtivo. Em que pesem os avanços decorrentes da lei n. 10.973, de 2004, considerada um marco da política pública de inovação no país, o que se observa é que esse processo de interação se encontra em ritmo e estágio bastante incipientes, o que é em certa medida corroborado pelo aumento da participação de bens e produtos de baixo valor agregado na pauta de exportações (IPEA, 2011).

Diante do exposto, reconhece-se que a educação desempenha papel estratégico em uma sociedade como a brasileira, que tem pela frente o desafio de promover o crescimento econômico com inclusão social, formar profissionais socialmente 
críticos e tecnicamente capacitados a atuar como agentes dessa transformação, muitas vezes, em contextos sociais extremamente adversos.

Justamente por se reconhecer o potencial transformador e estratégico da educação para alavancar o desenvolvimento é que se faz necessário ampliar sua efetividade e abrangência em favor dos segmentos socialmente alijados. Nesse sentido, entende-se que o tratamento igualitário entre desiguais tende a perpetuar desigualdades. Portanto, será necessário instituir, ampliar e aprofundar programas e ações que aportem insumos e investimentos adicionais e diferenciados aos grupos sociais mais vulneráveis.

Além de se conceber e executar a política educacional como parte das demais políticas públicas, deve-se ainda ter em conta especificidades dos grupos sociais a serem atendidos, especialmente as limitações decorrentes de suas frágeis formas de inserção social.

\section{CONSIDERAÇÕES FINAIS}

Conforme foi destacado no início deste artigo, não se concebe o desenvolvimento como condição que estaria disponível para todos os povos e países, sobretudo quando se tem por referência o padrão alcançado por aqueles que integram o chamado Primeiro Mundo, uma vez que o seu alcance resultou, em grande medida, da relação Centro-Periferia, ou seja, mediante determinados condicionantes histórico-estruturais do desenvolvimento capitalista que, por sua própria natureza, não são replicáveis no tempo.

Ao mesmo tempo, compartilha-se do entendimento de que a concretização desse padrão de desenvolvimento alcançado no Ocidente esteve intimamente associada à elevação do nível educacional nesses contextos societários. Entretanto, a equalização de oportunidades de acesso a uma educação de qualidade para todos, na fase atual do desenvolvimento capitalista, dificilmente será viabilizada a contento sem que se alterem pari passu as condições socioeconômicas, uma vez que a relação educação-desenvolvimento constitui uma via de mão dupla.

Em que pesem os indiscutíveis avanços logrados nos últimos anos, o Brasil ainda se apresenta como uma das nações mais desiguais do mundo e a educação constitui, dentre outros campos de intervenção social, um dos principais espelhos dessa sociedade profundamente desigual.

Apesar de todas essas desigualdades serem historicamente explicáveis pela natureza do processo civilizatório aqui instaurado, o rompimento com esse legado histórico deverá ser radicalizado, por meio da ação do Estado, como forma de se contrapor à dinâmica do mercado que favorece justamente aqueles que já se encontram em situação privilegiada.

À medida que o mercado se torna mais competitivo e, portanto, excludente, aumenta a demanda social pela ação do Estado em favor daqueles que ficam à sua 
margem, no intuito de corrigir ou ao menos compensar desigualdades geradas por meio dessa lógica excludente.

Em que pese o reconhecimento de que a educação traz consigo inequívoco potencial transformador da sociedade, acredita-se que tal potencial vem sendo pouco explorado, entre outros, pelo fato de a política educacional ser concebida e executada sem levar em conta as demais políticas públicas. Com isso, reduzem-se as chances de incorporação daqueles que, ao longo de tantas gerações, estiveram alijados do acesso a padrões de consumo e cidadania tidos como os mínimos aceitáveis.

O desafio passa a ser o de viabilizar a utilização de tal potencialidade para romper o círculo vicioso da pobreza. Desse modo, os que se encontram nessa situação precisariam ter acesso a uma educação diferenciada e de qualidade, lembrando-se que a qualidade da educação não se faz exclusivamente no âmbito da escola, mas depende de um conjunto de fatores extrínsecos a ela, como renda e padrões adequados de moradia, saneamento básico, transporte, alimentação etc.

Portanto, não bastaria apenas oferecer "boas escolas", no que concerne à infraestrutura e às instalações, aos professores e materiais didáticos, em quantidade suficiente e com padrão mínimo de qualidade àqueles que ainda se encontram alijados desses direitos sociais, ainda que tais condições sejam requisitos imprescindíveis para o bom rendimento e desempenho de qualquer estudante. Para que haja o efetivo usufruto desses insumos, também se faz necessário assegurar mínimas condições de acesso e permanência na escola, o que implicará alterar não só a estrutura e forma de distribuição da renda, mas também dos demais bens e serviços públicos que interferem na qualidade de vida e no bem-estar.

Em face da complexidade social brasileira e dos desafios no campo educacional, torna-se necessário definir alguns focos de atuação prioritária, sem perder de vista a natureza sistêmica da educação e, menos ainda, sem reeditar medidas adotadas no passado recente que acarretaram desinvestimentos nos níveis de ensino não obrigatórios, em particular na educação superior.

Entre os diversos desafios educacionais que se apresentam à sociedade brasileira, ao menos dois deles são considerados inadiáveis e cuja superação dependerá de engajamento de toda a sociedade. O primeiro corresponde à erradicação do analfabetismo entre adultos e idosos, uma espécie de "chaga nacional" que afeta sobretudo os mais pobres, idosos, negros, moradores de áreas rurais e a população nordestina. O segundo desafio é o de fazer valer o que estabeleceu a Constituição Federal brasileira de 1988: assegurar a obrigatoriedade do ensino fundamental a todos os brasileiros na faixa de 7 a 14 anos. Nesse caso, garantir a sua conclusão.

Se no plano jurídico-legal o Brasil avançou bastante no sentido de estabelecer a educação como direito de todos, a realidade tem se mostrado reticente em fazer valer esse direito constitucional, a exemplo do ensino obrigatório de oito anos. 
Apesar de esse último desafio não ter sido superado até o presente momento, o Congresso Nacional já incumbiu a sociedade brasileira de atingir metas ainda mais ousadas. Por intermédio da lei n. 11.114, de maio de 2005, o ensino fundamental foi ampliado de oito para nove anos de estudo, com início aos 6 anos de idade. Por sua vez, a EC n. 59, de 11 de novembro de 2009, ampliou a obrigatoriedade do ensino para a faixa etária de 4 a 17 anos, para abranger a pré-escola e o ensino médio.

Quando se deixa de fazer valer tais preceitos constitucionais, compromete-se não apenas a efetivação da cidadania, mas também as demandas de mercado e, em última instância, o desenvolvimento do país.

A baixa escolaridade tende a afetar de forma mais insidiosa a população mais pobre. Evidência disso é dada pelo significativo número de trabalhadores desempregados que procuram o Sistema Nacional de Empregos (SINE), mas que não conseguem preencher os postos de trabalho disponíveis por não disporem dos requisitos demandados.

Do mesmo modo, a incapacidade de ler e escrever limita as possibilidades de inserção profissional e aumenta a oferta de mão de obra para o exercício de funções de menor remuneração, o que contribui para achatar salários nessa categoria. Além de restringir o acesso a empregos mais valorizados, a baixa escolaridade, que corresponde ao chamado analfabetismo funcional, compromete a qualidade dos bens e serviços produzidos por esses trabalhadores.

A partir do que foi aqui analisado, pode-se concluir pela existência de forte associação entre o grau de desenvolvimento alcançado pelo país e o padrão educacional logrado pela população brasileira. $\mathrm{O}$ cotejamento de indicadores socioeconômicos e educacionais stricto sensu permitiu evidenciar tal vinculação entre rendimento escolar e alguns fatores ou dimensões da vida em sociedade, tais como renda familiar e situação nutricional de crianças e jovens. Além disso, ficou evidenciado que, via de regra, as escolas que atendem à população mais pobre, especialmente as localizadas no Nordeste e em áreas rurais, são também as que dispõem de piores condições infraestruturais e pedagógicas.

Portanto, o rompimento desse círculo vicioso, entre pobreza e baixa escolaridade, constitui condição sine qua non para que o país possa, de fato, alcançar um padrão de desenvolvimento aceitável. Talvez, mais do que em qualquer época, a superação desse desafio dependa da ampliação e intensificação da ação do Estado.

\section{REFERÊNCIAS}

Abramovay, Miriam; Castro, Mary G. Ensino médio: múltiplas vozes. Brasília: UNESCO; MEC, 2003.

ARRIGHI, Giovanni. O longo século XX: dinheiro, poder e as origens de nosso tempo. Rio de Janeiro: Contraponto; São Paulo: UNESP, 1996. 
Buareue, Cristovam. O que é apartação: o apartheid social no Brasil. São Paulo: Brasiliense, 1993.

Corbucci, Paulo R. O Brasil e a globalização: a renovada condição periférica. Brasília: Universa, 2003.

. Desafios da educação superior e desenvolvimento no Brasil. Brasília: IPEA, 2007 (Texto para Discussão n. 1.287).

Fausto, Boris; Devoto, Fernando Brasile Argentina: um ensaio de história comparada (1850-2002). São Paulo: Editora 34, 2004.

INEP. Sinopse do Professor de Educação Básica de 2009. Brasília, INEP. Disponível em: <http://www.todospelaeducacao.org.br/biblioteca/1381/sinopse-do-professor2009-do-ministerio-da-educacao/>. Acesso em: 13 dez. 2011.

IPEA. Inovações, padrões tecnológicos e desempenho das firmas industriais brasileiras (Org. por De Negri, J. A.; Salerno, M. S.) Brasília: IPEA, 2005.

46, 2011.

. O avanço das commodities. Desafios do Desenvolvimento, ano 8, n. 66, p. 40-

LASTREs, Helena M. M. Globalização e o papel das politicas de desenvolvimento industrial e tecnológico. Brasília: IPEA, 1997 (Texto para Discussão n. 519).

Mareues, Maria O. da S. Escola noturna e jovens. Revista Brasileira de Educação, n. 5/6, p. 63-75, 1997.

\section{SOBRE O AUTOR}

Paulo Roberto Corbucci é doutor em sociologia pela Universidade de Brasília (UnB). Técnico de planejamento e pesquisa do Instituto de Pesquisa Econômica Aplicada (IPEA).

E-mail: paulo.corbucci@ipea.gov.br

Recebido em agosto de 2011 Aprovado em setembro de 2011 
la producción y reproducción de la fuerza de trabajo, en situaciones de plusvalía absoluta $y$ de plusvalía relativa. Las mudanzas en el campo de la educación son referidos como la tentativa de inaugurar una nueva etapa en este proceso, a partir de la reorganización del capitalismo inaugurada en los años ochenta. Cuestiona la linealidad afirmada en la Teoría del Capital Humano entre la educación y el desarrollo económico, integrando en el análisis aspectos politicos relativos a las luchas y al rechazo de estudiantes a aprender lo que la escuela selecciona como relevante, asi como la resistencia de los profesores a las formas de trabajo a que están sometidos.

Palabras clave: reproducción de la clase trabajadora; masificación de la educación; valor de uso del cambio de la educación.

\section{PAULO ROBERTO CORBUCCI}

\section{Dimensões estratégicas e limites do papel da educação para o desenvolvimento brasileiro}

O propósito maior deste estudo é o de discutir a relação entre educação e desenvolvimento no contexto atual da sociedade brasileira, tendo-se em conta a condição sistêmica de uma economia altamente globalizada. Parte-se da premissa segundo a qual o desenvolvimento não é factível a todos os países, ao menos nos padrões alcançados no chamado Primeiro Mundo, mas também se reconhece que o desenvolvimento de uma nação não se concretiza sem uma educação de qualidade para todos. Questiona-se o poder de transformação social que tem sido atribuído à educação, uma vez que ela própria é, em grande medida, derivada das condições socioeconômicas. Busca-se analisar em que grau o padrão educacional brasileiro estaria comprometendo o desenvolvimento do país e como este, em seu estágio atual, afeta a qualidade da educação. Trata-se, pois, de analisar potencialidades e limites da educação diante do desafio de tornar o Brasil uma nação economicamente dinâmica e socialmente justa.

Palavras-chave: educação e desenvolvimento; relação centro-periferia; fatores socioeconômicos.

\section{Strategic dimensions and limits of the role of education for brazilian development}

The main purpose of this study is to discuss the relationship between education and development in the current context of Brazilian society, taking into account the systemic condition of a bighly globalized economy. It starts with the premise that development is not feasible for all countries, at least in the standards achieved in the so-called First World, but also recognizes that the development of a nation is not realized without a quality education for all. Place under discussion the power of social transformation that has been attributed to education, since it is itself largely derived from socioeconomic conditions. Seeks 
to analyze to what extent the Brazilian educational standard would be compromising the country's development and how this, in its current state, affects the quality of education. It is, therefore, to analyze the potential and limits of education face the challenge of making Brazil a nation economically dynamic and socially equitable.

Keywords: education and development; centre-periphery relation; socioeconomic factors.

\section{Dimensiones estratégicas y limites del papel de la educación para el desarrollo brasileño}

El propósito mayor de este estudio es el de discutir la relación entre educación y desarrollo en el contexto actual de la sociedad brasileña, teniéndose en cuenta la condición sistemática de una economía altamente globalizada. Se parte de la premisa según la cual el desarrollo no es posible a todos los países, al menos en los padrones alcanzados en el llamado Primero Mundo, pero también se reconoce que el desarrollo de una nación no se concretiza sin una educación de calidad para todos. Se cuestiona el poder de transformación social que ha sido atribuido a la educación, una vez que ella propia es, en grande medida, derivada de las condiciones socioeconómicas. Se busca analizar en que medida el padrón de la educación brasileña estaría comprometiendo el desarrollo del país y cómo éste, en su etapa actual, afecta a la calidad de la educación. Se trata, pues, de analizar potencialidades y límites de la educación delante del desafio de convertir a Brasil en una nación económicamente dinámica y socialmente justa.

Palabras clave: educación y desarrollo; relación centro periferia; factores socioeconómicos.

\section{LUIZ ANTÔNIO CUNHA}

\section{Contribuição para a análise das interferências mercadológicas nos currículos escolares}

$\mathrm{O}$ artigo almeja contribuir para o conhecimento do modo como se definem os currículos escolares no Brasil, com ênfase no setor público. Assumindo o pressuposto de que a débil autonomia do campo educacional brasileiro propicia a intervenção de forças externas a ele, o texto identifica duas vertentes do mercado - a econômica e a ideológica - como relevantes para se entender a heteronomia do campo educacional. A vertente ideológica abrange a instrumentalização de instituições educacionais para a inculcação de valores e padrões de comportamento definidos como legítimos por entidades privadas, tais como as religiosas e as partidárias. A vertente econômica compreende tanto a venda de mercadorias para consumo das instituições educacionais (a oferta gerando a demanda), quanto a reserva de mercado para profissionais, empresas e organizações não governamentais. $\mathrm{O}$ autor reconhece que ambas as vertentes são úteis para efeitos analíticos, mas adverte contra sua 